\title{
KEHIDUPAN RELIGI MASYARAKAT DI DAERAH PERBATASAN KABUPATEN KUNINGAN- KABUPATEN CILACAP (Religious Life of Communities in the Border of Kuningan Regency-Cilacap Regency)
}

\author{
Effie Latifundia \\ Balai Arkeologi Bandung, Jalan Raya Cinunuk KM 17, Cileunyi, Bandung \\ E-mail: yunda_effie@yahoo.com
}

\section{INFO ARTIKEL}

\section{Histori artikel}

Diterima: 25 Juli 2016

Direvisi: 19 Agustus 2016

Disetujui: 14 Oktober 2016

\section{Keywords:}

religion,

tradition megalithic,

sacred

\section{Kata kunci:}

religi,

tradisi megalitik, keramat

\begin{abstract}
Until now, in some villages in the border area of Kuningan-Cilacap people still support the megalithic tradition. Ancestor worship or veneration of ancestral spirits is a growing belief in the concept of megalithic culture, ie a culture that uses objects atu stone building as a means of rituals. This study aims to explore the remains of megalithic tradition which is still ongoing in the community to this day in some villages in the border area of Kuningan Regency, West Java to Cilacap, Central Java, and the media are to be used. This research was conducted by survey method to collect information and describe forms of cultural remains. The results showed although Islam has been embraced as a religion, but belief in ancestors as local religious understanding before Islam developed, ongoing, and maintained by several rural communities in the border. It can be concluded, that the less an area under the influence of the outside then resulting in stronger local element/dominant code of conduct rooted in the community, because it is already in progress in the long term.
\end{abstract}

\begin{abstract}
ABSTRAK
Sampai sekarang ini, beberapa desa di daerah perbatasan KuninganCilacap masyarakatnya masih mendukung tradisi megalitik. Pemujaan leluhur atau pemujaan terhadap roh nenek moyang merupakan suatu konsep kepercayaan yang berkembang pada kebudayaan megalitik, yaitu suatu kebudayaan yang menggunakan benda-benda atu bangunan dari batu sebagai sarana ritualnya. Penelitian ini bertujuan menggali sisa-sisa tradisi megalitik yang masih berlangsung dalam masyarakat hingga sekarang ini di beberapa desa di daerah perbatasan Kabupaten Kuningan (Jawa Barat) dengan Kabupaten Cilacap (Jawa Tengah), dan media apa saja yang digunakan. Penelitian ini dilakukan dengan metode survei untuk mengumpulkan informasi dan mendeskripsikan bentuk-bentuk tinggalan budayanya. Hasil penelitian menunjukkan meskipun Islam telah dianut sebagai agama namun kepercayaan terhadap leluhur sebagai paham religi lokal sebelum Islam berkembang, masih tetap berlangsung dan dipertahankan oleh beberapa masyarakat pedesaan di perbatasan. Dapat disimpulkan, bahwa semakin kurang suatu daerah mendapat pengaruh dari luar maka dapat mengakibatnya unsur lokal semakin kuat/dominan mengakar dalam tata laku dan kepercayaan masyarakatnya, karena hal tersebut sudah berlangsung dalam jangka waktu yang panjang.
\end{abstract}

\section{PENDAHULUAN}

Berdasarkan pendapat Leslie A. White yang dikutip Radam (2001), salah satu unsur yang membentuk religi, yakni keyakinan (belief), adalah salah satu bagian dari sistem idiologis. Sistem ini sendiri adalah salah satu wujud inti kebudayaan. Dengan demikian, religi adalah bagian dari dan terbentuk dalam ruang lingkup kebudayaan manusia (Radam, 2001: 1). Religi menghubungkan antara gejala supernatural dengan kehidupan sehari-hari, sehingga religi lebih berkaitan dengan ritual, mitos dan status (Prasetyo dkk, 2004: 1-2).

Dengan religi manusia bisa medapatkan ketenangan berupa kebutuhan sosial dan psikologis untuk menghadapi hal-hal di luar jangkauan 
pikirannya, seperti menjawab pertanyaan penting tentang terjadinya alam semesta, hubungan manusia dengan kekuatan alam, peristiwa kematian, penyakit, bencana dan lainlain (Prasetyo dkk, 2004: 3).

Selanjutnya menurut Koentjaraningrat, bahwa semua aktivitas manusia bersangkutan dengan religi berdasarkan atas suatu getaran jiwa disebut emosi keagamaan atau religious emotion. Emosi keagamaan yang mendorong melakukan tindakan yang bersifat religi. Emosi keagamaan menyebabkan suatu benda, suatu tindakan, suatu gagasan, mendapat suatu nilai keramat atau sacred value sehingga dianggap keramat. Semua bendabenda, tindakan-tindakan, gagasangagasan yang biasanya tidak keramat apabila dihadapai manusia yang dihinggapi emosi keagamaan hingga terpesona semua menjadi keramat (Koentjaraningrat, 1990: 376-377).

Keramat mengandung arti suci dan bertuah yang dapat memberikan efek magis dan psikologis kepada pihak lain (http://kbbi.web.id). Berdasarkan pemikiran dan konsep-konsep teori tersebut kemudian Koentjaraningrat mengajukan konsep religi menjadi lima komponen, dan masing-msing mempunyai peranan sendiri dan saling keterkaitan erat satu dengan lainnya. Komponen tersebut, yaitu emosi keagamaan, kepercayaan, ritus dan upacara, peralatan ritus dan upacara, serta umat agama (Koentjaraningrat, 1990: 376-379).

Masyarakat beberapa desa di daerah perbatasan Kuningan (Jawa Barat) - Cilacap (Jawa Tengah) mayoritas pemeluk Islam, akan tetapi dari hasil penelitian menunjukkan meskipun Islam telah dianut namun kepercayaan terhadap leluhur sebagai paham religi lokal sebelum Islam berkembangmasihtetapdipertahankan. Masyarakatnya berkeyakinan tentang adanya pemahaman tentang alam dan lingkungan roh, karena beranggapan bahwa hubungan roh dengan manusia yang hidup tetap berlangsung. Roh sangat berpengaruh dan dianggap memiliki kekuatan untuk membantu manusia dalam menaungi kehidupan. Untuk mengkomunikasikan keyakinankeyakinan tersebut melalui sesaji dan upacara. Prasetyo berpendapat, bahwa melakukan upacara itu sebagai kewajiban sosial, karena upacara sesaji sebagai upacara yang gembira dan meriah tetapi juga keramat, dan tidak sebagai suatu upacara yang khidmat (Prasetyo, 2004:5).

Karena pusat dari sistem religi dan kepercayaan di dunia adalah ritus dan upacara, dan melalui kekuatankekuatan yang dianggap berperan dalam tindakan-tindakan gaib itu, manusia mengira dapat memenuhi kebutuhannya serta mencapai tujuan hidup baik bersifat material maupun non material (Prasetyo, 2004: 6).

Pembahasan aspek religi tersebut berhubungan dengan aktivitas masyarakat masa lalu, yang mencerminkan pada bukti-bukti yang berwujud benda tinggalannya. Tinggalan benda masa lalu salah satunya adalah bangunan megalitik. Kebudayaan megalitik oleh para ahli cendrung dikaitkan dengan pemujaan terhadap roh nenek moyang (ancestor Worship) (Prasetyo, 2004:93).

Adapun bentuk-bentuk pemujaan kepada roh nenek moyang dan tata cara pelaksanaannya disesuai dengan masing-masing daerah. Tradisi megalitik merupakan bentuk tradisi megalitik tidak mengacu pada suatu era peradaban tertentu, namun lebih merupakan bentuk 
ekspresi yang berkembang karena adanya kepercayaan akan kekuatan magis atau non-fisik dan didukung oleh ketersediaan sumber daya di sekitarnya.

$$
\text { Kajian mengenai religi }
$$
bersangkut paut dengan aktivitas pada masyarakat beberapa desa di daerah perbatasan Kuningan-Cilacap tercermin melalui bukti yang berwujud benda-benda tinggalannya. Situssitus berlatar religi tersebut masih ditemukan di Desa Mandapajaya, Desa Bungurberes, dan Desa Sagaranten, yaitu desa-desa terletak di wilayah Kuningan bagian selatan berbatasan langsung dengan Kabupaten Cilacap, Jawa Tengah.

Tinggalan megalitik berupa monolit, punden berundak, batu tegak/ menhir sebagai penanda makammakam kuna, dan jenis batu lain yang dianggap suci atau keramat. Hal tersebut menunjukkan bahwa dalam masyarakat beberapa desa di daerah perbatasan masih berlanjut kepercayaan terhadap roh leluhur dan adanya berbagai mitos. Hampir semua situs-situs religi oleh masyarakat dikeramatkan. Ritual dilakukan pada sistus-situs tersebut apabila desa akan mengadakan kegiatan, seperti pemilihan kepala desa, hiburan/pesta tradisional (dadung), pajak bumi, hajatan, membangun rumah, atau pindah rumah. Ritual dipimpin sesepuh desa atau juru kunci dan pengunjung atau peziarah membawa sesaji. Tujuan ritual meminta barokah, keselamatan, kesejahteraan lewat media situs-situs yang diakui bernilai religius tersebut.

\section{Berdasarkan kenyataan}

tersebut, permasalahan yang diangkat pada tulisan ini adalah, untuk mengungkap situs-situs tradisi megalitik yang masih berlangsung hingga sekarang ini, dan berhubungan dengan konsepsi religi. Penelitian ini bertujuan menggali sisa-sisa tradisi megalitik yang masih berlangsung dalam masyarakat hingga sekarang ini di beberapa desa di daerah perbatasan Kabupaten Kuningan (Jawa Barat) dengan Kabupaten Cilacap (Jawa Tengah), dan media apa saja yang digunakan.

\section{METODE}

Berdasarkan tujuan yang
ingin dicapai, tulisan ini bersifat
deskriptif. Pengumpulan rata
dilakukan dengan cara survei,
penelusuran literatur dan informasi-
informasi lain terkait fenomena yang
dikaji melalui wawancara dengan
masyarakat setempat. Dalam tulisan
ini menggunakan analisis morfologi,
analisis konstektual menyangkut
bentuk, fungsi, makna dan lingkungan
alam.

\section{PEMBAHASAN}

\section{Situs-Situs Bernilai Religius}

Survei arkeologis di beberapa desa kawasan perbatasan Kabupaten Kuningan- Kabupaten Cilacap tepatnya di Desa Mandapajaya, Desa Bungurberes, dan Desa Sigaranteun menemukan situs-situs religi bercirikan ritual masih digunakan oleh masyarakat pendukungnya. Situssitus religi tersebut dianggap keramat dan suci sehingga masih terpelihara hingga sekarang ini. Situs Situ Hulu Dayeuh berada di Dusun Kliwon, Desa Mandapajaya, Kecamatan Cilebak. Situs berada di perbukitan lahan milik desa, dengan luas areal $300 \mathrm{~m}^{2}$. Keletakan situs beradapada posisi $07^{\circ} 10^{\prime} 21.26^{\prime \prime}$ Lintang Selatan dan $108^{\circ} 32^{\prime}$ 54.25" Bujur Timur, dengan ketinggian $438 \mathrm{~m}$ di atas permukaan laut.

Penanda Situ Hulu Dayeuh 
berupe monollt bentuk detar tldak beraturan beruluran panjang $95 \mathrm{~cm}$, terleber $50 \mathrm{~cm}$, tinge $25 \mathrm{~cm}$. Arti stfu dalam kamus bahasa Indonesla adalah danau kecil, den hute adalah kepala. Sedangkan dalam bahasa Sunda, hutu dayouh diartikan gebagai pusat kotanya lbu kole. Istllah butu dayeuhisd mulal tarditeksl abed ko-8 Masehl dongan ditomukannye prasestl Kawrall. Selanjutryya prasast hutu dayeuh di Cirebon yang beresal dari abad ke-10 Masehl. Prasast batu tuls Bogor abad k9-14 Masehi tidak secara langsung menyobutken lstllah dayouh, namun kronik-kronik palaut Portıgis momperkuet keberadaan doyeuth untuk menyebutkan lbu Kota Pakuan Pajajaran (http: /pusalit2.petra.acid). Apablla Stuu Hulu Dayeuh dlhubungkan dengan arti dalam kamus bahasa Indonesta, dan bahasa Sunda maka dl gitus tersebut tidak ditemukan praseasti yeng menyatakan stau mendukung berupa danau kecll atalu pusat kota.

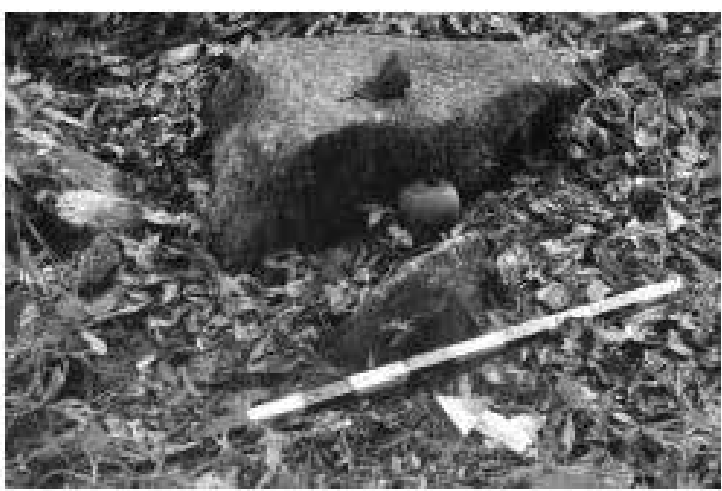

Gamber 1. Situ Hulu Dayouh (dolumenteas Bdai Avkoologi Bandung)

Sltu Hulu Dayeuh Mandapalaya dapat dikatakan semacam pusat kekuatan mlstls karena dllkeramatkan oleh masyarakatnya. Kekeramatan eteu sura mlstls senget terase apablle berada di areal situs. Hingga sekarang InI tldek setu orangpun beranl mengganggu pohon-pohon besar yang tumbuh di areal situs. Di sekitar betu monolt ditemukan bekas sesall yang dlbewa pengunjung berupe rokok dan kelapa muda. Pendatang yang berkunjung ke situs betu datartmonolit bersifat perorangan, dan kelompok. Situs Hulu Dayeuh ketaknyz cukup jauh dengan permukman penduduk. Apablla masyarakat Deasa Mandapajaya akan mengedeken suetu keglatan sepertl pesta dading, pernillhan kepala desa, menyambut herther beser yang mellbatkan masyarakat umum, maka ritural ke situs torsebut membewr seveaji berupa kemenyan, kelapa muda, telor agin, rokokfcenutu dengan tujuan minta keselamatan den kemudahan. Doa bersame dipimpin sesepuh desa/juru kuncl. Hingga sekerang masyarakat Mandapajaya percaya kalau tempat. itu bukan harnya sekedar batu tanpe art, sesall Itu dltunjukkan untuk leluhur terutame yeng menghuni Situ Hulu Dayeuh. Oleh sebab Itu, sltu Hulu Dayeuh Mandapajaya tetap terpalihara den keglatan retuel torus bertangsung hlingga sekarang.

Monolit lainmya bercirikan
rellglus mosin berade dl Dese
Mandapajaya adalah sttus Tatapakan. Siturg Tatapakan di Dusun Kliwon tepatryy terletak dl depan Kantor Desea Mendepejeyra di areal Masjid Desa. Keletakan stus berada pada posisi $07^{\circ} 10^{\prime} 22.31^{\prime \prime}$ LS den $108^{\circ} 32^{\prime}$ $51.60^{\prime \prime}$ BT, dengen ketingglen $633 \mathrm{~m}$ dpl. Batu datar (monollt) bahan andesitt tddek beraturan berukuran penjeng 48 $\mathrm{cm}$, lebar $30 \mathrm{~cm}$ dan tinggl $20 \mathrm{~cm}$. Stus Tatapakan sangat dikeramatkan oleh masyarakat setempat, dlberl cungkup dan torletak di areal magijd dese.

Keglatan ittual pada Shtus Tetapekan hingeg selcarang torus berlangsung sepert masyarakat melekukannya pada situs Situ Hulu Dayeuh. Apablla masyarakat Desa Mandepajaya bermaksud akan mengadaken suatu keglatan etau 
keramalan, sepertl ulang tahun desa, pesta dadung, pemilihan kepala desa dan lelnnya masyeraket pendukungnya terlebih dahulu meminta restu keselamatan, keamanan dengan membewa sesell ke sltus tersebut Sesaji yand dibawa sama seperti Sltu Hulu Dayeuh berupa kemenyen, kelapa muda, tolor asin, rokok/cerutu, doa bersama dipimpin sesepuh desa.

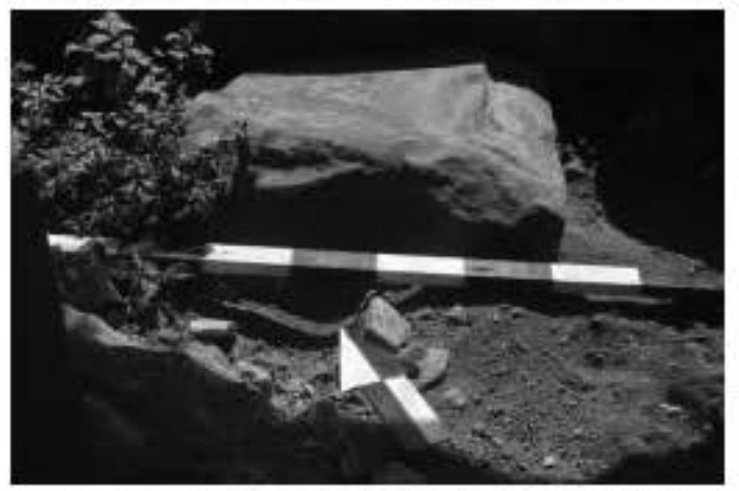

Combar 2. Sthus Tatapakan (dokuments:s Balal Arkeolod Bandung]

Istllah tatapekan dalam masyarakat Sunda, bukan hal yang baru. Tatapakan, yaltu batu persegl (balok) yang berfungsi sebagai kakd tang rumah panggung. Pada umumnya bangunan rumah adat Sunda bentuknya panggung dan bangunan tdak seluruhnya menempel pada tanah, tetapi dihubungkan dengan tiang yang disangog batu persegi (belok) yang dlsebut betu totepaken. Apabila terjadi gempa, getarannya diredam oleh batu tatapakan sehlngga meakjpun bangunan turut bergetar, rumah relatif dapat bertahan menerima beben getaran sempal kekuatan tertentu (http-J/sukustunda.heck.in). Thdak mendapat Jawaban apablla menghubungkan tatepakan dalam istilah Sunda dengan situs Tatapakan masyarakat Desa Mandapajaya.

Masih di kawasan Mandapajaya, stus dlkunjungl untuk keglatan thual lalnnya balah stus Kabuyutan. Name lain masyarakat menyebutnya Buyut
Yuda berada dl Ingkungan Dusun Kliwon, Desa Mandapajaya di lahan tenah millk desa. Keletakan stus Kaburyutan berade pada posias $07^{*}$ $10^{\prime} 18.42^{\circ}$ LS dan $108^{\circ} 32^{\prime} 53.63^{\circ}$ BT. dengen ketingglen $450 \mathrm{~m}$ dpl. DI areal situs Kabuyutan terdapat tipa batu breksl dengan beragam bentuk dalam posisi sejajar. Batu-1, bentuk bulat berdiameter $15 \mathrm{~cm}$, sebelah barat betur-1 dengen Jerak $20 \mathrm{~cm}$ terdapet batu-2, bentuk lonjong tidak beraturan berukuran panjang $100 \mathrm{~cm}$, lebar 45 $\mathrm{cm}$, tinggl $23 \mathrm{~cm}$. Sebelah tmur batu-1 jarak $8 \mathrm{~cm}$ terdapat batu-3 bentuk oval berdlemeter $10 \mathrm{~cm}$. Sltus Kebuyuten masih sering didatangi pengunjung terutama bagl masyarakat yang bermaksud melaksenakan hejatan, membangun rumah, atau pindah rumah. Pezlerah membewa sesall meminta barokah, kesejahteraen dan keselamatan.Pada areal situs benyak dltemukan seberan keplngln uang logam merupakan salah salu bentuk sesall yang dlbawa oleh para pengun]ung/pazlarah.

Dalam masyarakat Sunda kata kabuyuten sudah lame dikenel merujuk pada tempat-tempat tertentu yang dlanggap sakral. Wujudnya blsa berupa bengunan, lahan terbuka yang ditumbuhi pepohonan. Wlayah Kanekes dl Kecematan Leumidamar, Banten, adalah salah satu contoh kabuyutan Sunda (http:/ c.jpekudarmaraja.co.ld).

Sabagai tempat kegiatan
rellglus, kabuyutan
memperlihatkan salanya
Jełak kebudayaan Sundayana dl
Parahyangan. Kadeng-kadang tempat tersebut disebut mondata. Dalam naskah Carta Parahyangan tersirat bahwra kata kabuyuten adalah tempat yang dianggap mempunyai tuah. 


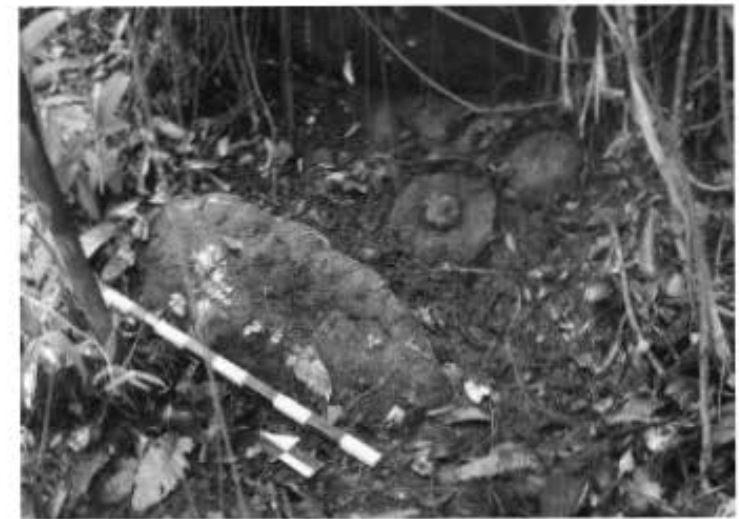

Gambar 3. Sltus Kabuyutan (dokumentas| Balai Avkeologi Bandung )

Banyak situs-situs Kabuyutan yang dibangun oleh leluhur Sunda di berbagal daerah dl seluruh wllayah Tatar Sunda. Biasanya situs-situs tersebut ditempatkan di lokasi yang sangat penting dan menjadi sumber kehidupan manusia diantaranya di sumber mata air, gunung, hutan, pinggir sungai (daerah aliran sungai), bukit, lembah, situ/embung, telaga, dan tempat-tempat penting lainnya. Leluhur Sunda sangat mewantiwanti agar seluruh kabuyutan di Tatar Sunda dilindungl, dlpellhara, dijaga kelestariannya agar dapat dimanafaatkan secara berkelanjutan untuk kesejahteraan dan kemakmuran hidup bersama.

Menurut Munandar (1992) yang dikutip Ekadjati mengatakan, bahwa lokasi kabuyutan itu kemungkinan dilengkapi dengan bangunan sarana ibadat, seperti batur tunggal, punden berundak. Hal tersebut masih dapat disaksikan pada sarana ibadat yang terdapat di Kanekes, untuk meyelenggarakan muja atau upacara keagamaan orang Kanekes mendatangl Sasaka Pusaka Buana dan Sasaka Domas adalah lokasi dipercaya yang paling suci, letaknya di dalam hutan (leuweung larangan) (Ekadjati, 2005: 192).

Demikian pula kiranya Situs
Kabuyutan Mandapajaya yang berada dl areal lahan yang dltumbuhl pohonpohon besar dan tumbuhan liar yang disakralkan oleh masyarakat hingga sekarang tetap terpelihara, dan terus berlangsung kegiatan ritual oleh pendukungnya.

Hasil survei di kawasan Mandapajaya, selain monolit, dan batu-batu dianggap keramat dan suci ditemukan pula dua (2) makam kuno Islam yang dikeramatkan. Masyarakat setempat menyebutnya makam keramat Blru dan makam keramat Subayan. Makam keramat Biru berada di Blok Cileles, Dusun Wage, Desa Mandalapajaya. Wujud fisik makam sangat sederhana, penanda makam berupa nisan batu tegak (menhir) sedikit miring ke timur, dan di kelilingi batu-batu alam andesit yang sudah berlumut. Orientasi makam utaraselatan. Pada areal situs terlihat baru saja didatangi pengunjung berziarah dengan meletakkan sesaji berupa kelapa muda, cerutu/rokok, nasi ketan, mata uang dan lainnya. Tujuan pengunjung berziarah ke makam keramat BIru terutama menglngInkan kesembuhan dari segala penyakit, naik pangkat/abatan, kekayaan/rezeki. Situs terletak di areal tanah keramat milik desa dengan lingkungan ditumbuhi pohon kawung, rotan, dan bambu dan sering didatangi pengunjung.

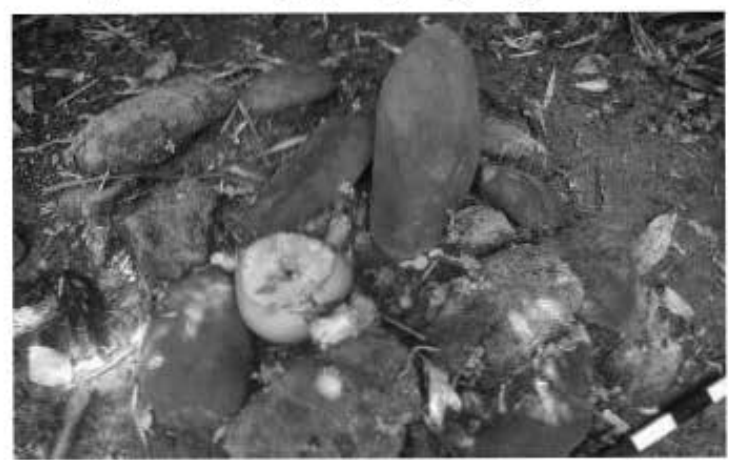

Gambar 4. Makam Keramat Biru (dokumentasi Balai Arkeologi Bandung) 
Makam kedua adalah makam keramat Subayan berada di Dusun Wage, Desa Mandapajaya. Makam berada di lahan milik Wardo, areal dikellingi sawah penduduk terletak dl tepl Sungal Cljolang. Posisl lahan keramat Subayan sedikit lebih tinggi dari lahan areal yang ada di sekitamya. Penanda makam berupa batu tegak tidak beraturan di kelilingi batubatu alam, orlentasl utara-selatan. Keramat Subayan sering dikunjungi peziarah dengan maksud dan tujuan hampir sama dengan makam keramat Cibiru, yaitu meminta keberkahan, keselamatan dan rezekl/kesejahteraan. Makam sering didatangi peziarah dari kawasan sekitar desa.

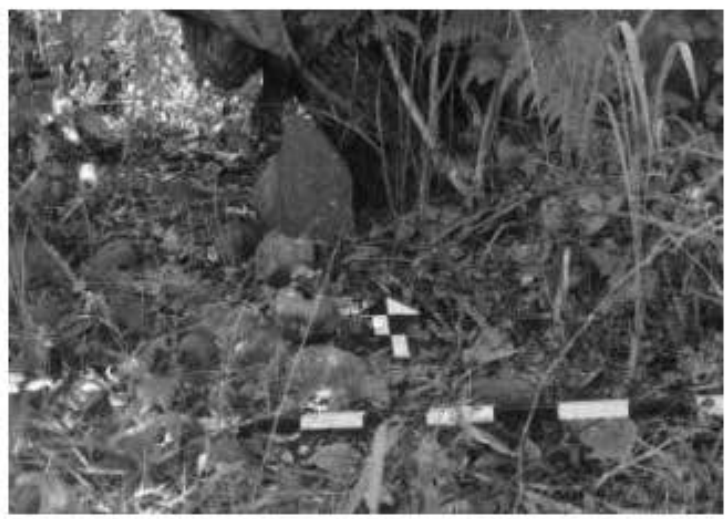

Gambar 5. Keramat Subayan (dokumentasi Balai Arkeologi Bandung

Survei dan deskripsi selanjutnya diteruskan di Dusun Bangbayang, Desa Bungurberes, Kecamatan Cilebak. Topografis Dusun Bangbayang, Desa Bungurberes berbuklt-buklt dengan tebing yang curam dan termasuk dalam subsatuan morfologi pebukitan terjal. Darl data Informasl wlayah Kuningan, bahwa desa tersebut berpotensi rawan bencana tanah longsor tingkat tinggi. Jalan yang sangat terjal sering rusak karena kondisi alam yang tidak mendukung karena tanah labll. DI Dusun Bangbayang, Desa Bungurberes ditemukan tinggalan tradisi megalitik berada di puncak bukit masyarakat menyebutnya Situs Pasarean. Situs Pasarean berada dl tengah areal hutan cukup gelap, ditumbuhi pohonpohon besar dengan luas lahan $40 \mathrm{~m}^{2}$. Keletakan Situs Pasarean pada posisi $07^{\circ}$ 08' 27.39' LS dan $108^{\circ} 36^{\prime}$ 54.48." BT. dengan ketinggian $861 \mathrm{~m}$ dpl. Menurut cerita masyarakat setempat dan keterangan juru kunci bahwa di areal ini dahulu tempat pertemuan atau berkumpulnya para ulama untuk membahas strategi penyebaran agama Islam. Para ulama datang dari berbagai pelosok, yaltu dart Clrebon, Banten, Luragung, Tasikmalaya, Tangerang, Purwakarta.

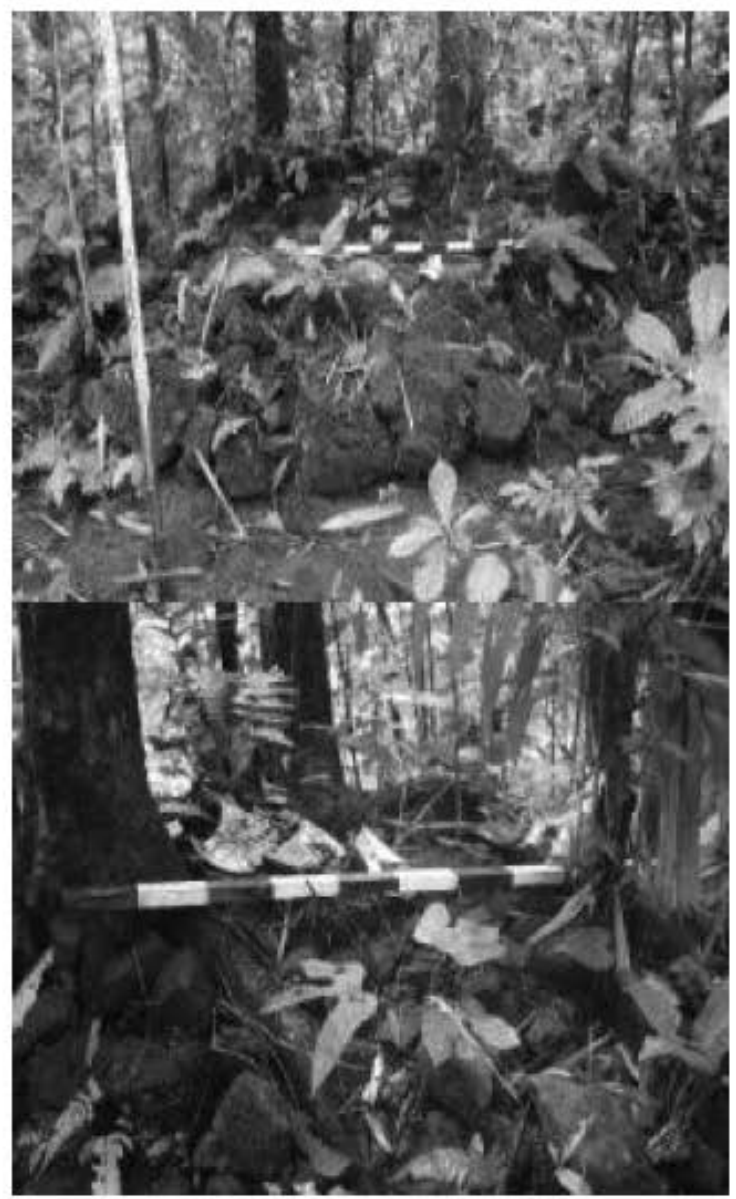

Gambar 6. Makem Buyut Jangkung dan Makam Sljagangtanggur (dokumentasl Balal Arkeologl Bendung )

Situs merupakan punden berundak berterap lima. Pada areal situs paling atas terdapat dua gundukan/tumpukan batu alam bercampur batuan breksi merunjung menyerupai makam. Juru kunci mengatakan ini adalah makam Mbah 
Buyut Jangkung dan makam Pangeran Sijagangtanggur. Kedua makam tidak memakai nisan dengan orientasi ke dua makam timur-barat. Walau Situs Pasarean berada dl lokasl yang sangat jauh dari perkampungan penduduk berada di perbukitan yang tinggi, situs tetap saja didatangi pengunjung atau peziarah. Hal tersebut terbukti dari bekas-bekas sesaji yang terdapat di areal makam. Biasanya Pengunjung yang datang mempunyal maksud dan tujuan tertentu.
Lebih kurang $200 \mathrm{~m}$ ke arah utara dari situs makam Buyut jangkung dan Sijagangtanggur terdapat Situs Mbah Buyut Jurusimpan dan Pangeran Kuyuput Putlh.Sltus berada dl tengah hutan kecil ditumbuhi pohon beringin, hantap, kawung dan kupa dengan luas lahan situs $20 \mathrm{~m}^{2}$. Areal makam sekarang ini sudah tertutup akar-akar pohon yang menyebar luas. Keletakan situs berada pada posisi $07^{\circ} 08^{\prime} 22.80^{\prime \prime}$ LS dan $108^{\circ} 40^{\prime} 05.26^{\prime \prime}$ BT dengan ketinggian $846 \mathrm{~m} \mathrm{dpl}$.

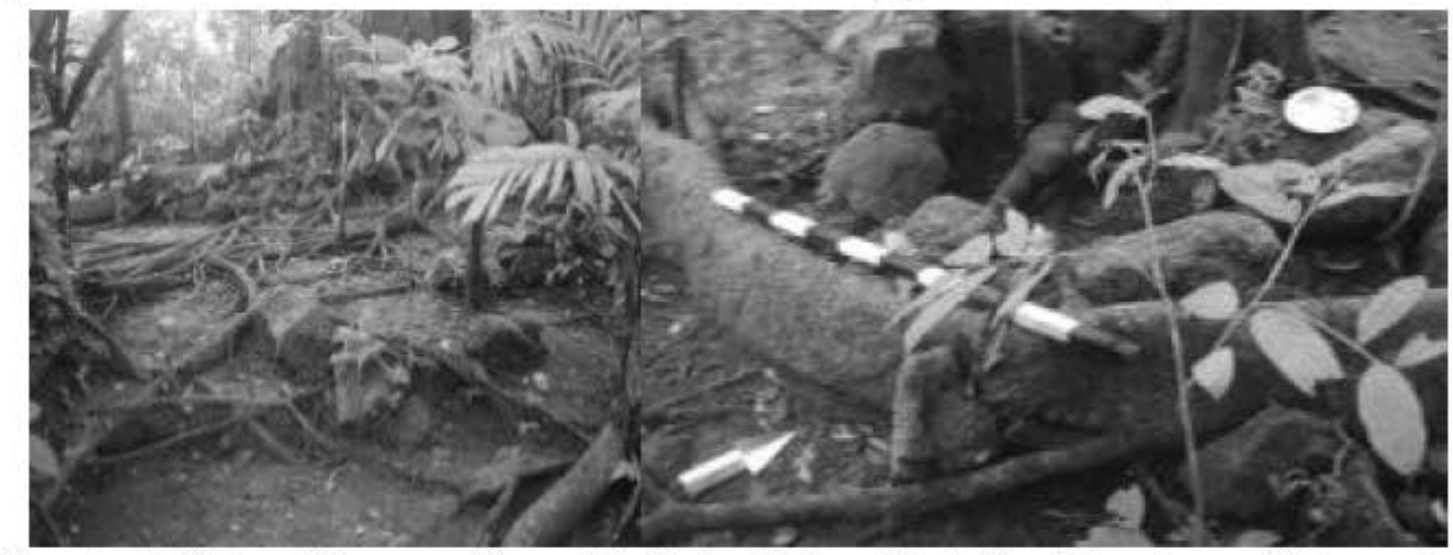

Cambar 7. Makam Pangeran Kuyuput Putlh dan Makem Mbah Buyut Jurusimpan (dokumentas! Balal Arkeologl Bandung )

Penanda ke dua makam berupa susunan batu alam ditutupi lumut membentuk empat persegi panjang dan kondisi batu sudah terdesak akar-akar pohon yang ada. Orientasi makam timur-barat. Makam sering dikunjungi masyarakat setempet maupun pendatang dari luar daerah dengan membawa sesaji yang sudah ditentukan yaitu berupa telor asin, nasi ketan, kopi, teh, rokok dan doa dipimpin Juru kuncl. Tujuan pengunjung/pezlarah biasanya meminta kesejahteraan, dan keselamatan.

Selanjutnya survei dan deskripsi juga diarahkan ke kompleks makam keramat Gunung Sagara berada di Dusun Sagara, Desa Sagaranten, Kecamatan Ciwaru.Topografis Dusun Sagara, Desa Sagaranten berbukitbukit dengan tebing yang curam dan termasuk dalam subsatuan morfologi pebukitan terjal. Data informasi wilayah Kuningan menyatakan bahwa Desa tersebut termasuk kawasan rawan bencana tanah longsor terutama bila terjadi hujan deras. Situs kompleks makam keramat berada dl buklt Wates. Di balik Bukit Wates Desa Sagaranten terdapat Dusun Cibeberapa, Desa Cilumping, Kecamatan Dayeuh Luhur, Kabupaten Cilacap (Jawa Tengah).

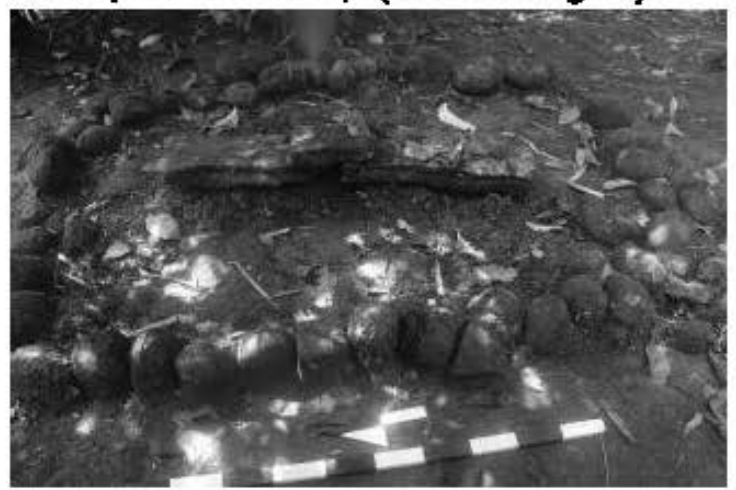

Gambar 8. Makam Buyut Sagara (dokumentasi Balai Arkeologi Bandung) 
Menurut cerita kepala desa, dahulu para penjual parang/golok, pisau dan alat-alat pertanian lainnya datang dari Cilacap berdagang ke dusun mereka menuruni bukit Wates, akan tetapi untuk sekarang ini sudah jarang ada.

Kompleks makam Keramat Gunung Sagara jauh dari pemukiman penduduk terletak di perbukitan dengan luas lahan $200 \mathrm{~m}^{2}$ milik desa. Keletakan situs berada pada posisi $07^{\circ} 06^{\prime}$ '48.09" LS dan $108^{\circ} 38^{\prime} 30.75$." BT dengan ketinggian $372 \mathrm{~m}$ dpl. Sebelah timur kompleks makam di bawah perbukitan mengalir Sungai Cisagara. Tokoh yang dimakamkan di kompleks Makam Keramat Gunung
Sagara terdiri Aria Jakatawa, Buyut Sagara, Aria Sutajaya, Buyut lebay, Buyut Jembrong. Orientasi makam utara-selatan. Khusus nisan penanda makam Buyut Sagara batu pipih bentuk empat persegi panjang dalam kondisi roboh. Pengunjung yang datang berziarah biasanya mempunyai maksud dan tujuan tertentu dan dilengkapi membawa sesaji berupa nasi ketan, kopi, telur asin, cerutu, komplang/wajid, ikan gabus pindang. Doa biasanya dipimpin juru kunci. Makam hingga sekarang sering didatangi peziarah, hal ini terbukti di areal makam ditemukan sesaji berupa makanan dan cerutu.

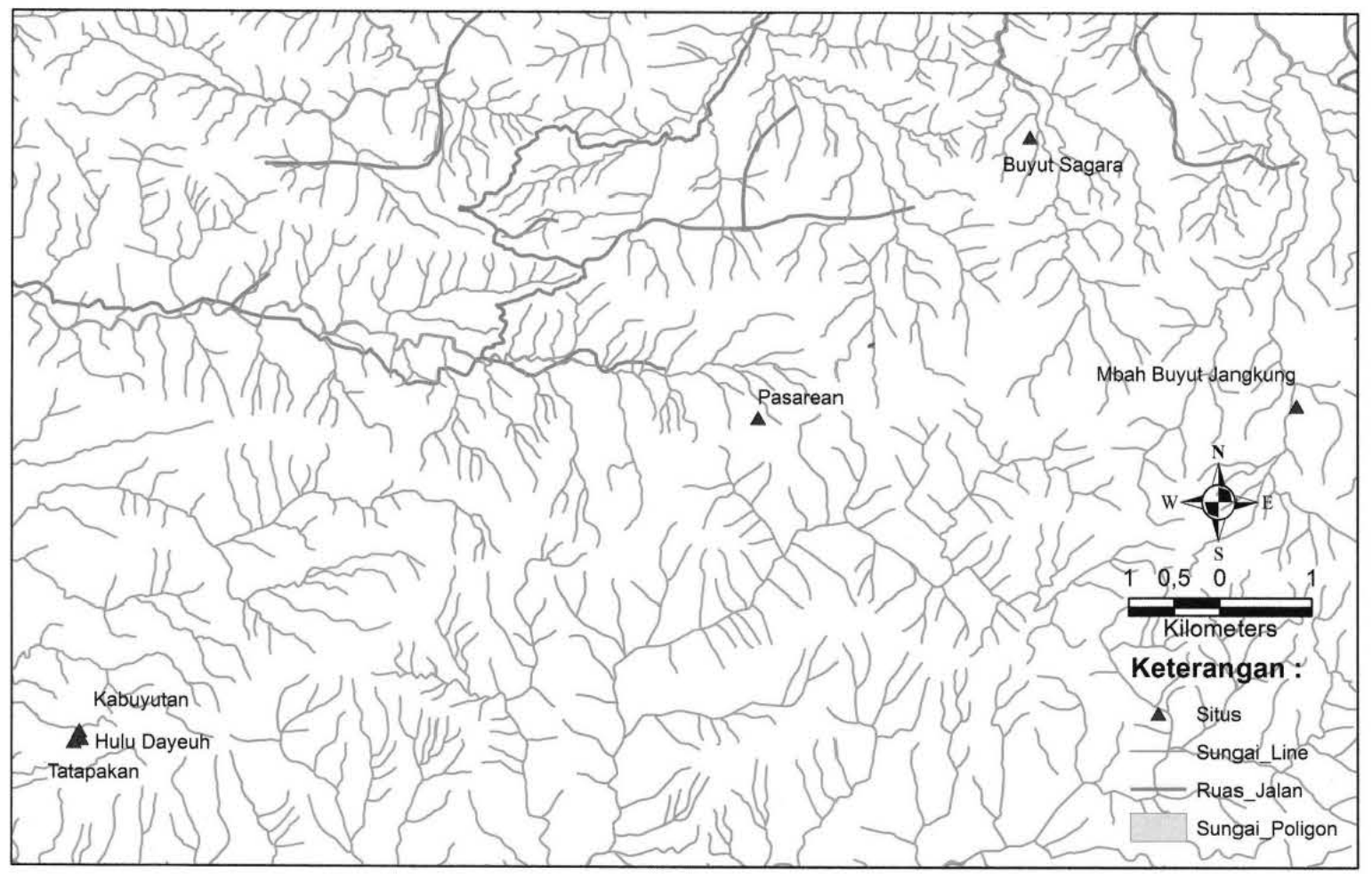

Gambar 9. Peta Sebaran Situs-Situs Religi di Daerah Perbatasan Kuningan-Cilacap (Sumber: Balai Arkeologi Bandung)

Religi dan Kehidupan

Sebelum Islam hadir dan berkembang masyarakat Nusantara telah memiliki kepercayaan kepada arwah nenek moyang. Dinamisme merupakan kepercayaan bahwa semua benda mempunyai kekuatan gaib, yaitu merupakan unsur religi yang berkembang di tengah kehidupan masyarakat Nusantara yang dilandasi dengan kayakinan bahwa di luar diri manusia ada kekuatan lain.

Religi erat hubungannya kepercayaan yang menganggap 
bahwa arwah nenek moyang atau arwah leluhur sangat menentukan dalam kehidupan manusia. Adanya anggapan bahwa hubungan antara roh dengan manusia yang masih hidup tetap berlangsung. Kepercayaan kepada kekuasaan arwah leluhur, pada waktu berkembangnya tradisi megalitik dianggap mempunyai kekuatan gaib dan dapat menolak kekuatan jahat, serta dapat memberikan kesejahteraan kepada masyarakat terutama kepada keturunannya. Demikian halnya masyarakat Sunda pada masa prasejarah sudah mengenal yang gaib. Roh yang berasal dari manusia generasi sebelumnya disebut sebagai roh nenek moyang atau roh leluhur, yang dapat memancarkan kekutan gaib yang berdampak baik atau buruk pada mausia yang masih hidup. Agar terhindar dari kekuatan gaib berdampak buruk, maka dilakukan pemujaan.

Sewaktu masuk ajaran Hindu-Buddha penduduk Sunda berkenalan dengan gaib lain, yaitu Dewa. Ternyata konsep ketuhanan berasal dari kepercayaan terhadap arwah leluhur serta agama Hindu-Buddha belum memuaskan, sehingga lahirlah gagasan baru mengenai konsep Tuhan dinamai Hiyang. Hiyang berarti hilang, yang gaib. Konsep hiyang berpangkal dari makna dan proses terbentuknya roh dalam kepercayaan leluhur (Ekadjati, 2005: 176-177). Agar masyarakat selalu terlindungi, maka arwah leluhur harus diperlakukan sebaik mungkin, karena roh dianggap memiliki kekuatan untuk membantu manusia dalam menjalankan kehidupan.
Hasil penelitian di Desa Mandapajaya, Desa Bungurberes dan Desa Sigaranteun kawasan di daerah perbatasan KuninganCilacap konsep kepercayaan tersebut masih terus berlanjut. Untuk mengatasi masalah yang dirasa tidak mampu atau menggelisahkan mengatasinya dengan memanipulasi kekuatan supernatural. Keyakinan ini bersangkut paut dengan aktivitas dalam masyarakatnya, dan terbukti dan terwujud pada bendabenda tinggalan budayanya. Tinggalan budaya berupa monolit, dan makam-makam kuna dengan penanda nisan batu tegak/menhir dianggap suci atau keramat. Masyarakat pendukungnya mengasumsikan bahwa fungsi tinggalan budaya tersebut berkaitan dengan pemujaan, penguburan, lambang pemimpin, dan penolak bala. Mereka mengakui adanya pengaruh positif baik secara materi maupun spiritual apabila berkunjung pada situssitus suci dan keramat tersebut. Oleh karena itu pada situs-situs tersebut diadakan kegiatan ritual disertai sesaji baik dilakukan secara perorangan maupun kelompok mohon bantuan pada dunia supernatural.

Ritual dan sesaji pada situssitus keramat akan dilakukan apabila masyarakat Desa Mandapajaya akan mengadakan suatu acara dan sifatnya melibatkan seluruh masyarakatnya, seperti pemilihan kepala desa, hiburan/pesta tradisional (dadung), pajak bumi, hajatan dan lainnya. Situssitus religius yang dikunjungi seperti yang sudah diuraikan terdahulu, yaitu Situ Hulu Dayeuh, Situs Tatapakan, Situs Kabuyutan. Hal yang sama dilakukan pula bagi yang akan membangun rumah, pindah lokasi tempat tinggal baik secara 
perorangan maupun kelompok, terlebih dahulu berziarah atau mengunjungi situs-situs tersebut. Dalam kegiatan ritual pengunjung membawa sesaji. Sesaji yang di bawa berupa kemenyan, kelapa muda, telor asin, rokok/cerutu.Tujuan dari ritual adalah meminta barokah, keselamatan dan kesejahteraan. Situs-situs tinggalan budaya tersebut berfungsi sebagai sarana pemujaan terhadap roh para leluhur.

Demikian halnya dilakukan para peziarah yang datang ke makammakam keramat dengan dilandasi niat dan tujuan yang didorong kemauan batin yang kuat dan mantap. Motivasi kuat peziarah adalah permohonan pintu rizki, dimudahkan usahanya, kenaikan pangkat/kedudukan, sembuh dari berbagai penyakit dan lainnya. Kunjungan disarankan membawa sesaji berupa nasi ketan, kopi, telur asin, cerutu, komplang/wajid, ikan gabus pindang. Kegiatan ritual diakhiri dengan doa bersama yang dipimpin oleh sesepuh/tokoh desa. Oleh karenanya, aspek religius magis dalam masyarakat dianggap suatu kebutuhan dan sangat menentukan dalam perjalanan kehidupan.

Jika melihat keletakan makammakam keramat yang tersebar di Desa Mandapajaya, Desa Bungurberes, dan Desa Sagaranten ditempatkan di lokasi perbukitan dengan ketinggian tertentu tampaknya dapat dijelaskan berdasarkan sudut pandang arkeologis. Menurut penjelasan Ambary, selain didasarkan pada pengaruh unsur budaya megalitik, bahwa lokasi ketinggian dianggap sebagai wilayah sakral atau suci dalam tatacara pemakaman (Ambary, 1991: 13).

Makam-makam kuno terdapat di beberapa desa kecenderungan unsur megalitis masih sangat dominan tampak pada bentuk nisan makam berupa batu tegak menyerupai menhir berukuran sedang dan kecil dalam bentuk persegi panjang, pipih dan bulat atau lonjong. Menurut Kartodirjo (1975) yang dikutip Wuri Handoko, menjelaskan bahwa menhir dalam alam kepercayaan masyarakat megalitik berfungsi sebagai medium penghormatan, menjadi tahta kedatangan roh, sekaligus lambang dari orang-orang yang diperingati. Dengan demikian kontinuitas tradisi megalitik yakni penggunaan menhir sebagai nisan kubur, menandai karakteistik Islam yang sangat akomodatif terhadap paham-paham lokal yang merupakan bentuk kepercayaan terhadap leluhur yang diwarisi sejak zaman megalitik dan terus bertahan hingga persentuhannya dengan Islam (Handoko, 2014: 37).

Menhir merupakan tinggalan tradisi megalitik yang sangat banyak ditemukan di berbagai situs dan berbagai masa setelah periode Neolitik, yang terus berkembang hingga masa pengaruh Hindu, Islam bahkan hingga masa sekarang (Sukendar, 1983:93). Menhir atau batu tegak, menurut Sukendar (1983) secara umum mempunyai tiga fungsi: yaitu batu tegak yang berfungsi dalam upacara penguburan, upacara pemujaan dan batu tegak yang tidak berfungsi religius (Sukendar, 1983: 100). Sedangkan menurut Wiyana, bahwa pemberian tanda berupa menhir pada masa prasejarah dan nisanpada masa Islam, secara prinsip mempunyai kesamaan, yaitu sebagai tanda adanyapenguburan (Wiyana, 2008:311).

Berdasarkan hal tersebut, menunjukkan bahwa masyarakat beberapa desa di daerah perbatasan 
disatu pihak masyarakat telah mendapat pengaruh budaya Islam, namun kepercayaan lokal dengan medium benda-benda megalitik tetap bertahan dan terus hidup oleh para pendukungnya. Menurut pendapat Ambary (1986), yang dikutip Wuri Handoko hal tersebut memperlihatkan kesinambungan dengan anasir budaya pra Islam disebut sebagai permanensi etnologis. Permanensi bentuk makam dan nisan yang cenderung megalitis menunjukkan determinasi budaya Islam sangat kurang (Handoko, 2014, 43).

Mungkin saja perkembangnya Islam berjalan sangat lamban dalam masyarakat desa-desa di daerah perbatasan terjadi karena faktor lingkungan alam. Karena lokasi desadesa tersebut berada di pedalaman, perbukitan, dan kawasan terpencil,

\section{PENUTUP}

Dari uraian di atas dapat diketahui kehidupan religi dalam masyarakat beberapa desa di daerah perbatasan Jawa Barat-Jawa Tengah yaitu tepatnya daerah perbatasan Kabupaten Kuningan dengan Kabupaten Cilacap. Masyarakat masih berpegang teguh pada kepercayaan adat istiadat leluhurnya. Keyakinan dalam hidupnya diwujudkan dengan tindakan berkunjung ketempat yang dianggap keramat. Tempat-tempat keramat dianggap memiliki kekuatan gaib dan mistik sehingga sering diziarah dengan membawa sesaji. Masih hidupnya unsur-unsur lokal, yaitu tradisi pralslam menampakkan adanya kompromi kultural dalam masyarakat Desa Mandapajaya, masayarakat Desa Bungurberes dan masyarakat Desa Sigaranteun yang berlokasi di daerah perbatasan Kabupaten Kuningan, Jawa Barat yang hingga sekarang ini saja sangat sulit untuk dikunjungi. Semakin kurang suatu daerah mendapat pengaruh/ kontak budaya dengan luar, maka dapat mengakibatkan unsur lokal semakin kuat/dominan mengakar dalam tata laku dan kepercayaan yang dianut masyarakatnya, karena sudah berlangsung dalam jangka waktu yang panjang. Hal tersebut terbukti pada masyarakat Desa Mandapajaya, masyarakat Desa Bungurberes, dan masyarakat Desa Sagaranteun, yaitu desa- desa berlokasi di kawasan perbatasan, meskipun Islam terus berkembang namun budaya lokalyang cenderung megalitis sulit atau bahkan mungkin tak bisa dihilangkan. Aspek religius magis dalam masyarakat dianggap suatu kebutuhan dan sangat menentukan dalam perjalanan kehidupan.

dengan Kabupaten Cilacap, Jawa Tengah. Fenomena pola keletakan situs di perbukitan, penempatan situs jauh dari pemukiman, situs di areal punden berundak, penanda makam menhir (batu tegak) sebagai nisan, upacara dan ziarah makam, hal ini semua menunjukkan kehidupan religi tradisi pra Islam. Menggambarkan masih kuatnya pengaruh religi pada masyarakat setempat, setiap langkah kehidupan dilakukan ritual yang bersifat sakral dengan beragam rupa sesaji yang harus disiapkan.

Melalui penelitian arkeologi membantu mengungkap sejarah budaya masyarakat desa-desa di daerah perbatasan. Masyarakat perbatasan yang tergolong jauh dari pengaruh budaya luar masih melanjutkan budaya lokal walaupun Islam telah berkembang di kawasan tersebut menarikuntukselalu diungkap. Hal tersebut menggambarkan bahwa 
Islam sangat adaptif terhadap unsurunsur lokal.Terlihat bahwa Islam dengan budaya lokal memiliki salah satu kesamaan yaitu sama-sama memiliki ritual yang hidup di masyakat. Terungkap bahwa Islam di daerah perbatasan berakulturasi dengan tradisi dan kepercayaan terhada preligi lama, yakni kepercayaan terhadap arwah leluhur, yang hidup jauh sebelum Islam hadir dan tidak merobah nilainya dengan masih melakukan ritual dan sesaji di situs-situs yang dikeramatkan oleh pendukungnya. Hasil penelitian menunjukkan meskipun Islam telah dianut masyarakat desa-desa di daerah perbatasan sebagai agama namun kepercayaan terhadap leluhur sebagai paham religi lokal sebelum Islam berkembang, masih tetap berlangsung dan dipertahankan 


\section{DAFTAR PUSTAKA}

Ambary, Hasan Muarif.1991. "Makam-makam Kesultanan dan Parawali Penyebar Islam di Pulau Jawa". Aspek-aspekArkeologi Indonesia No.12. Jakarta: Pusat Penelitian Arkeologi Nasional.

Ambary, Hasan Muarif. 1998. Menemukan Peradaban, Jejak Arkeologis dan Historis Islam Indonesia. Jakarta: Logos Wacana IImu.

Ekadjati, Edi S. 2005. Kebudayaan Sunda Zaman Pajajaran Jilid 2. Bandung: Pustaka Jaya

Handoko, Wuri. 2014. "Tradisi Nisan Menhir pada Makam Kuno Raja-Raja di Wilayah Kerajaan Hitu". Kapata Arkeologi Vol. 10 No. 1. Balai Arkeologi Ambon.

Koentjaraningrat. 1990. Pengantar Ilmu Antropologi. Jakarta: PT. Rineka Cipta.

Prasetyo, Bagyo, dkk. 2004. Religi Pada Masyarakat Prasejarah di Indonesia. Jakarta: Puslit Arkenas.

Radam, Noerid Haloei. 2001. Religi Orang Bukit.Yogyakarta: Yayasan Semesta.

Sukendar, Haris. 1983. "Peranan Menhir dalam Masyarakat Prasejarah di Indonesia". Proseding Pertemuan IImiah Arkeologi III. Jakarta: Pusat Penelitian Arkeologi Nasional. HIm. 92-108.

Sukendar, Haris. 1981. Peninggalan Tradisi Megalitik di Daerah Cianjur, Jawa Barat. Jakarta: Pusat Penelitian Arkeologi Nasional.

Wiyana, Budi. 2008. "Dari Menhir ke Nisan: Suatu Dinamika Budaya". Kumpulan Makalah Pertemuan IImiah Arkeologi. Kediri, 23-28 Juli 2002. Jakarta: IAAI.

\section{INTERNET}

Http://kbbi.web.id diakses pada 15 Mei 2016.

Http: //puslit2.petra.ac.id diakses pada 3 Maret 2016.

$\mathrm{Http}: / /$ limbangangarut.com diakses pada 5 April 2016.

Http://sukusunda.heck.in diakses pada 18 April 2016. 